\title{
Hospitals as professional organizations: challenges for reorientation towards health promotion
}

Christina C. Wieczorek, Benjamin Marent, Fran Osrecki, Thomas E. Dorner and Wolfgang Dür

Published in: Health Sociology Review (2015) 24, 2: 123-136

http://dx.doi.org/10.1080/14461242.2015.1041541

\begin{abstract}
Health promotion, as one tool of hospital managers to reorient hospitals towards more clientoriented healthcare services, has been emphasized for almost three decades. Yet, it is recognized that change in hospitals is challenging and is more desired than substantially enacted. To overcome organizational challenges, health promotion has, so far, adapted organizational change strategies primarily applied in business organizations. However, in this paper, it is argued that such strategies do not adequately reflect the nature of hospitals as 'professional organizations'. To gain a better understanding of the challenges for health promotion reorientation, this paper combines wellestablished theories from the sociology of professions and organizational science. These theories provide a useful framework that advances the role of professionals as powerful agents within any reorientation efforts in hospitals. This framework guided the narrative review of empirical literature on critical dimensions along which professionals engage with reorientation efforts in hospitals. Accordingly, specific managerial strategies to facilitate health promotion reorientation are formulated. With its theoretical underpinnings and related empirical studies, the paper offers a new perspective on the challenges of implementing health promotion and proposes strategies that may help hospital managers to push forward health promotion reorientation in their organizations.
\end{abstract}

Keywords: hospital; professional organization; professionals; health promotion; sociology; implementation

Introduction

The reorientation of hospitals towards health promotion is widely recognized as a core strategy to develop quality within service provision, and, with respect to the rise of chronic diseases, an important factor for sustained health and quality of life (Pelikan, Dietscher, Krajic, \& Nowak, 2005; Pelikan, Dietscher, \& Schmied, 2013). Such reorientation involves a complex process whereby the whole organization, its corporate identity, its structure and culture, and its physical environment are adjusted towards health promotion (Garcia-Barbero, 1998). Comprehensive changes are required because the healthcare sector should move 'beyond its responsibility for pro-viding clinical and curative services', as already postulated by the Ottawa Charter for Health Promotion (World Health Organization, 1986, p. 3). Health, in this context, is understood as a positive (resource-oriented) concept rather than a negative (disease-oriented) concept as proposed by the biomedical model and, thus, promoting health stands for 'enabling people to increase control over and to improve their health' (World Health Organization, 1986, p. 1). The best-known example for a comprehensive health promotion reorientation in hospitals is the Health Pro-moting Hospitals Network, which was 
established by World Health Organization (WHO) in 1990 to support health promotion implementation and to facilitate organizational change (Groene \& Garcia-Barbero, 2005; Pelikan, Krajic, \& Dietscher, 2001). Since its launch, the network has spread around the globe and now consists of more than 900 members in more than 40 countries.

However, it is recognized that health promotion reorientation in the hospital sector is difficult to achieve. When hospitals are expected to reorient their formal structures and work routines towards health promotion, the actual level of organizational change often does not meet initially set requirements: evidence shows that a systematic reorientation of hospitals often remains very limited (Whitehead, 2004; Wise \& Nutbeam, 2007). In the literature, it is emphasized that hospi-tals' reorientation towards health promotion is still more a desirable goal than an organizational reality (De Leeuw, 2009; Johnson \& Baum, 2001). Healthcare professionals' reluctance to inte-grate health promotion within their work routines with clients (read: patients) has been indicated as a major barrier to health promotion implementation (Lee, Chen, Chien, et al., 2014; Lee, Chen, \& Wang, 2014; Whitehead, 2004). In this way, Lee, Chen, and Wang (2014) conclude that health promotion in hospitals has been accepted as an ideal, endorsed by administrative staff members, but a devoted ground workforce is lacking.

To overcome these problems and to facilitate health promotion implementation, it is largely organizational change strategies that have been applied. These include (a) organizational development (e.g., Grossman \& Scala, 1993; Pelikan, 2007), (b) total quality management (e.g., Brandt, Schmidt, Dziewas, \& Groene, 2005), and, more recently, (c) organizational capacity-building, such as the provision of resources and knowledge (e.g., Hawe, Noort, King, \& Jordens, 1997). However, the success of these strategies in supporting health promotion implementation has remained limited because - as we argue - the nature of hospital organizations is not adequately reflected within such strategies. Organizational change strategies, originally developed for business organizations, most often rely on a 'machine model' of organizations that work along top-down, control-oriented and output-standardized structures and processes. Hospitals, however, are more adequately described by a very different model. This is the 'pro-fessional organization' that is expert-driven, skillsoriented, and based on professional-client interactions that are very hard to monitor and supervise by organizational management.

In this paper, we will conceptualize hospitals as professional organizations to acquire a better understanding of the challenges of reorienting hospitals towards health promotion. Therefore, we will combine well-established theories from the sociology of professions and organizational science: Andrew Abbott's (1988) theory of professions will be used to outline the nature of pro-fessional work and Henry Mintzberg's $(2012,1979)$ model of the professional organization will be applied to describe how autonomous professional labour at the organizational core has signifi-cant consequences for the organizational structure and the management of hospitals. This frame-work advances the understanding of the role of professionals as powerful agents within any efforts to reorientate hospitals. Moreover, the role of professionals in enacting change has hitherto been understudied in the health promotion literature. Using the framework as a lens, we will conduct a narrative review on current organization studies and ask how professionals' decisions about their engagement with implementing new programs in hospitals are patterned. In other words, we will 
explore critical dimensions along which professionals' engagement with reorientation efforts in hospitals can be understood.

Reviewing the empirical literature, we will show that professional autonomy as described by Abbott and Mintzberg still prevails. Therefore, comprehensive program implementation within hospital organizations significantly relies on whether individual professionals are willing to engage with reorientation efforts. In summarizing the literature, we have identified three critical dimensions for analysing professionals' engagement with program implementation: pro-fessionals' status, professionals' practices, and professionals' role-definitions. Considering these three dimensions, we will outline specific strategies that can support health promotion implementation. By combining sociological theories and related empirical organization studies, this paper offers a novel perspective on the challenges of introducing health promotion principles and programs within hospital organizations. In portraying hospitals as professional organizations and reframing strategies for health promotion implementation, this paper may provide a further important step towards reorientation in the hospital sector.

Professional work, organizational structure, and the challenge of managing hospitals

Our analysis of hospitals begins by elaborating the specific conditions and characteristics of professional work that is performed within a hospital's operative core. Thereafter, we will outline the specific consequences that this kind of work has for the structuring of a hospital which, therefore, can be understood as a specific type of organization, namely a 'professional organization'. Against the background of this framework, the challenges of managing reorientation and change in hospitals will be reconstructed (see Figure 1).

To elaborate how professional work, particularly in hospitals, differs from that of other occu-pations, we have selected a specific task-oriented approach from the extensive literature of the sociology of the professions (for an overview compare: Saks, 2010). For this article, Andrew Abbott's (1988) theory of professions is used because this approach emphasizes the particularities of professional work. According to Abbott (1988), professions are 'exclusive occupational groups applying somewhat abstract knowledge to particular cases' (p. 8). Thus, traditionally, professional work addresses the personal problem of individualized clients. Furthermore, the problems for which individual clients seek professional help are often existential and complex problems, such as the risk to health, that clients cannot solve themselves (Stichweh, 1997; Vanderstraeten, 2007). By treating clients' personal problems, professionals are defining, shaping, or altering the personal attributes of their clients and these treatments take place under conditions of uncertainty and risk.

A further aspect we can extract from Abbott's definition is that professional work is based on abstract knowledge which is acquired over long periods of (university-based) education and (practice-based) training (Abbott, 1988, p. 52). The practice-based training constitutes an essen-tial part of the education of each profession because scientific knowledge cannot be applied in a purely 
routine fashion, but requires a case- and situation-specific adaptation. Professionals have to understand the uniqueness of each client, while, at the same time, subsuming their clients' problems under the scientific classifications of their profession. The specific problem of any client can only be taken into consideration with close face-to-face-interactions where professionals become acquainted with clients and can apply their abstract knowledge in a particular way (Abbott, 1988, p. 44). These interactions are based on the shared expectation that clients trust the professional's competency and altruism and are willing to cooperate with the professional's instructions (Parsons, 1969).

From these features of professional work follows the claim for professional autonomy, the exclusive right to control specific work activities (Abbott, 1988, p. 59). The complexity of the individual case and the existential problem for which the client seeks help from a pro-fessional makes this kind of work hard for hospital managers to routinize and monitor. More-over, professionals argue that nonprofessional groups lack the competence - the abstract knowledge - to control their work practices and only the 'collegial community' can carry out this function.

The nature of professional work has a significant impact on the structuring of organizations as suggested by Henry Mintzberg $(2012,1979)$. He portrayed organizations in which the core work is carried out by professionals, such as hospitals, universities, or law firms, as 'professional bureaucracies' (1979) and more recently conceptualized them as 'professional organizations' (2012). Within professional organizations, the operative core is the key organizational com-ponent. Therein professionals use their knowledge, skills, and attitudes, which they have acquired over long periods of academic education, training, and indoctrination. However, the standards according to which professionals categorize and treat their clients largely originate from outside the organization, e.g., from academic institutions and professional associations (Min-tzberg, 1979, p. 364). Since the actual application of these standards in specific situations implies autonomy and discretion, professionals can make themselves relatively independent of the organization in which they work and try to buffer their work from external (non-professional) inspection. Managerial attempts to observe or evaluate professional-client interactions are norma-tively refused by underlining the confidentiality and intimacy of these situations as well as by arguing that self-regulation by insiders (professional peers) is more appropriate than regulation by non-professionals, such as clinical managers or policymakers (Freidson, 2001; Mintzberg, 1979, p. 364). 


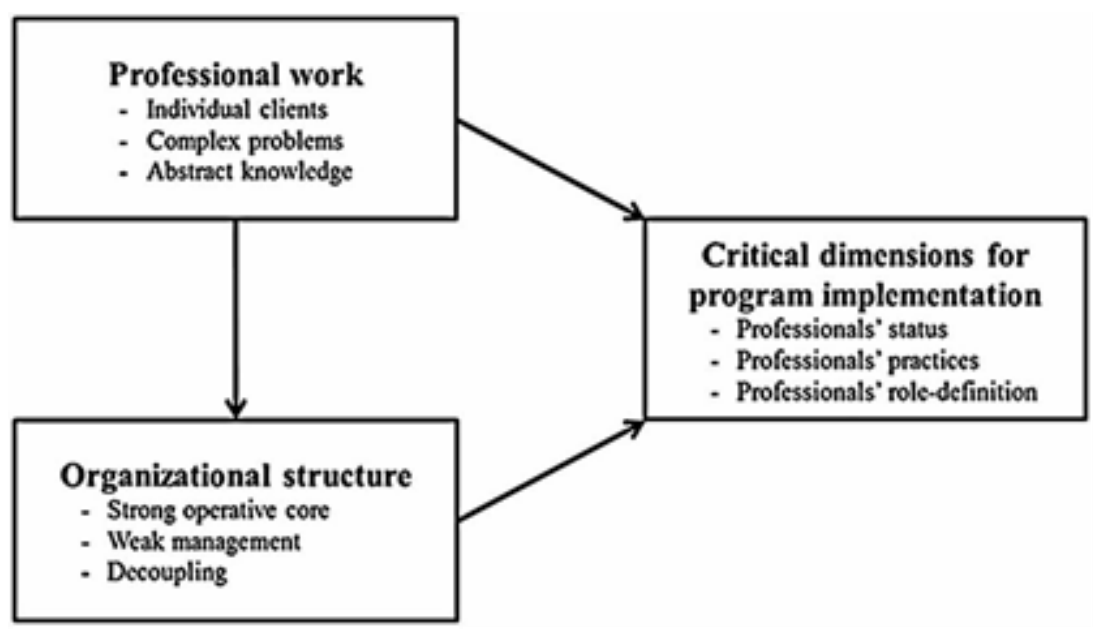

Figure 1. Framework representing challenges of program implementation in hospitals.

By contrast to professional practices that are oriented towards autonomy, self-regulation, and client orientation, managerial practices are oriented towards principles of standardization, effi-ciency, and control. Yet, by comparison to the prominence of the operative core, the management in professional organizations is relatively weak with regards to enforcing control over pro-fessional work processes (Mintzberg, 1979, p. 363). As the values and expertise of professionals are well established and firmly rooted in science and professional associations, they cannot easily be questioned by managerial authority. Therefore, managerial planning, in general, and efforts towards reorientation and change, in particular, are often absorbed by professional work practices within the operative core. In this way, Mintzberg (1979, p. 363) states that the operative core in professional organizations is largely decoupled from the organization's management structure. Certainly, professional organizations have a bureaucratic command structure at their disposal, personal attributes of their clients and these treatments take place under conditions of uncertainty and risk.

A further aspect we can extract from Abbott's definition is that professional work is based on abstract knowledge which is acquired over long periods of (university-based) education and (practice-based) training (Abbott, 1988, p. 52). The practice-based training constitutes an essen-tial part of the education of each profession because scientific knowledge cannot be applied in a purely routine fashion, but requires a case- and situation-specific adaptation. Professionals have to understand the uniqueness of each client, while, at the same time, subsuming their clients' problems under the scientific classifications of their profession. The specific problem of any client can only be taken into consideration with close face-to-face-interactions where professionals become acquainted with clients and can apply their abstract knowledge in a particular way (Abbott, 1988, p. 44). These interactions are based on the shared expectation that clients trust the professional's competency and altruism and are willing to cooperate with the professional's instructions (Parsons, 1969).

From these features of professional work follows the claim for professional autonomy, the exclusive right to control specific work activities (Abbott, 1988, p. 59). The complexity of the individual case and the existential problem for which the client seeks help from a pro-fessional makes this kind of work hard for hospital managers to routinize and monitor. More-over, professionals argue that non- 
professional groups lack the competence - the abstract knowledge - to control their work practices and only the 'collegial community' can carry out this function.

The nature of professional work has a significant impact on the structuring of organizations as suggested by Henry Mintzberg $(2012,1979)$. He portrayed organizations in which the core work is carried out by professionals, such as hospitals, universities, or law firms, as 'professional bureaucracies' (1979) and more recently conceptualized them as 'professional organizations' (2012). Within professional organizations, the operative core is the key organizational com-ponent. Therein professionals use their knowledge, skills, and attitudes, which they have acquired over long periods of academic education, training, and indoctrination. However, the standards according to which professionals categorize and treat their clients largely originate from outside the organization, e.g., from academic institutions and professional associations (Min-tzberg, 1979, p. 364). Since the actual application of these standards in specific situations implies autonomy and discretion, professionals can make themselves relatively independent of the organization in which they work and try to buffer their work from external (non-professional) inspection. Managerial attempts to observe or evaluate professional-client interactions are norma-tively refused by underlining the confidentiality and intimacy of these situations as well as by arguing that self-regulation by insiders (professional peers) is more appropriate than regulation by non-professionals, such as clinical managers or policymakers (Freidson, 2001; Mintzberg, 1979, p. 364).

By contrast to professional practices that are oriented towards autonomy, self-regulation, and client orientation, managerial practices are oriented towards principles of standardization, effi-ciency, and control. Yet, by comparison to the prominence of the operative core, the management in professional organizations is relatively weak with regards to enforcing control over pro-fessional work processes (Mintzberg, 1979, p. 363). As the values and expertise of professionals are well established and firmly rooted in science and professional associations, they cannot easily be questioned by managerial authority. Therefore, managerial planning, in general, and efforts towards reorientation and change, in particular, are often absorbed by professional work practices within the operative core. In this way, Mintzberg $(1979$, p. 363) states that the operative core in professional organizations is largely decoupled from the organization's management structure. Certainly, professional organizations have a bureaucratic command structure at their disposal, but several authors have pointed out that this structure can be understood as a negotiated order (Mintzberg, 1979; Strauss, Schatzman, Ehrlich, Bucher, \& Sabshin, 1963; Weick, 1979). This means that it can be bypassed as soon as the professionals have the impression that administrators and managerial efforts are not effectively serving their needs with respect to autonomy, discretion, or availability of resources. In professional organizations, professionals are largely buffering their practices from managerial inspection and such efforts create a decoupling of formal strategies and daily routines. Accordingly, management efforts at adopting new organizational policies do not necessarily change organizational behaviour. Now, several authors have argued that the domi-nance of professionals, in particular in medicine, has decreased over the last few decades by emphasizing concepts of deprofessionalization (e.g., Elston, 2004, 1991; Haug, 1988) or prole-tarianization (Mc Kinlay \& Arches, 1985). However, these approaches have been criticized for being preoccupied with formal organization and tend to underplay the interactional features and micro-practices in professional organizations (Numerato, Salvatore, \& Fattore, 2012) where decoupling still takes place and shields professional work from managerial control. While shifts in the relationship between the state and professionals are evident, medical domi-nance and autonomy has been transformed rather than 
diminished and the medical profession still is a high-status profession, which has maintained its power, at least on a micro-level in every-day practices in hospitals (Allsop, 2006; Armstrong, 2002).

Forms of decoupling between management and the operative core remain pivotal, as shown in a recent literature review by Numerato et al. (2012). The authors emphasize that managerial attempts to introduce new guidelines or control measures often remain merely formal procedures, which are not readily implemented as part of the organizational behaviour i.e., in daily routines of health professionals. Similarly, Correia (2013), as part of his study in Portugal, shows that despite several efforts to make the behaviour of professionals more predictable to hospital managers, professionals' autonomy has hardly changed and the influence of managers appears tenuous, especially with respect to professionals' daily work.

The organizational structures and processes of hospitals are characterized by professionals who are fairly autonomous and who significantly decouple their daily work from hospitals' organ-izational management structures. As a consequence, management in hospitals has only limited opportunities to guide and control the implementation of organizational change, such as reorientation towards health promotion, within the operative core because, on this level, professionals have the autonomy to decide if and how they are going to engage with reorientation efforts.

In the following, we will review recent organizational studies to identify critical dimensions for understanding professionals' engagement with organizational change. By summarizing the findings of these studies, managerial strategies to support the implementation of health promotion in hospitals will ultimately be derived.

Critical dimensions for professionals' engagement with program implementation

Following our conceptual framework, we explore critical dimensions along which professionals' engagement with reorientation efforts in hospitals can be understood. As reorientation efforts, including health promotion, are not per definition welcomed by professionals, it seemed impor-tant to study the ways in which professionals respond to the introduction of programs for change. However, the question of how professionals support or hinder health promotion reorien-tation in hospitals has been underexposed within the health promotion discourse. Therefore, we reviewed recent organization studies that investigated professionals' engagement within reorien-tation efforts (Ferlie, Fitzgerald, Wood, \& Hawkins, 2005; Levay \& Waks, 2009; McGivern \& Ferlie, 2007; Powell \& Davies, 2012; Saario, 2012; Timmons, Coffey, \& Vezyridis, 2014). In particular, we reviewed articles that (a) studied organizational change programs directed at chan-ging health professionals' daily routines; (b) explored change programs originating from outside professional associations (studies focussing on professional self-standardization, with evidence-based medicine as the archetype of professional self-standardization, have not been considered); and (c) showed how professionals' decisions to engage with or resist reorientation are constructed. 
As a result of several group discussions, we integrated and summarized the outcomes of these studies into three critical dimensions for understanding professionals' engagement with program implementation (see Figure 1):

- Professionals' status: Emphasizing status puts the focus on how organizational change programs fit into competitive relationships between professionals.

- Professionals' practices: Practices involve the question of how organizational change programs fit into professionals' daily work routines.

- Professionals' role-definition: Role-definition relates to how organizational change programs are compatible with professionals' self-perception.

In a further step, we used these dimensions to extrapolate particular strategies that could facilitate reorienting hospitals towards health promotion.

Professionals' status

The status of health professionals corresponds to their degree of professionalization - with medical specialists at the high end and auxiliary nurses at the lower end of this continuum. Two studies (Powell \& Davies, 2012; Timmons et al., 2014) support the hypothesis that the implementation of change programs is mediated by the professionals' status. Timmons et al. (2014) analysed how staff from an emergency department (ED) in the UK responded to the implementation of lean methods, which included e.g., the process of allocating patients to differ-ent areas of the ED as well as staff rotas. Semi-structured interviews, primarily with doctors and nurses, showed that staff appreciated the implementation of lean methods because, for example, it facilitated patient flow into and through the ED. Data revealed that staff were eager to adopt elements of lean methods for two reasons: first, implementation gave rise to organizational pro-fessionalism in emergency medicine; and, second, interviewees felt that it enhanced emergency medicine's somewhat lower status as compared to other medical specialists. Similar findings are presented by Powell and Davies (2012), who conducted a qualitative study in three UK hos-pitals on anaesthesiologists' and nurses' responses to the implementation of acute pain services. Nurses largely implemented new painmanagement services because these were seen as strengthening their position vis-à-vis doctors. By comparison, anaesthesiologists largely resisted because they saw pain management as a low-status task which would not enhance their pro-fessional standing within the organization. Pain was perceived as a highly subjective and hard-to-cure condition. 
Both studies show that externally determined organizational change programs are not necess-arily perceived as a threat to professionals, but may also be viewed as a potential resource. Pro-fessionals may champion change programs if they perceive that acquiring new skills, tasks, and responsibilities can enhance their professional status. Enhancement of status can either be seen in comparison to other professional groups, such as doctors and nurses, or within the same pro-fession.

Implementation of change programs seems to become more likely when professionals expect career opportunities or enhancement of their professional status as a consequence of imple-menting the particular program.

Professionals' practices

A second critical dimension, through which professionals' engagement with the implementation of change programs can be understood, is the match of such programs with professionals' prac-tices. Saario (2012) studied professionals' resistance to various managerial reforms by interview-ing health practitioners in Finnish psychiatric clinics. The author concluded that professionals resisted the implementation of administrative guidelines because they perceived it to be imposs-ible to keep up with them, particularly due to their excess number. Moreover, professionals cri-ticized these guidelines as a procedural façade without implications and benefit for client care. McGivern and Ferlie (2007), who conducted a qualitative study in two large British hospitals, found a broad range of responses to the introduction of the so-called 'consultant appraisal' forms. These forms demanded that professionals continuously report on their performances. Data revealed that consultant appraisal was put into practice by professionals who viewed the process as developmental. Participants considered the program to be a new opportunity to reflect on and review personal (individual) as well as organizational practices. Others viewed this as a tool that could be protective in future litigation. However, some professionals, who initially welcomed appraisal, felt the appraisers were then dismissive or the organization was unable to change the issues revealed through the appraisal. Resistance came particularly from pro-fessionals who perceived the collection of data in appraisal forms and their discussion with the appraiser to be a waste of time and as interfering with their autonomy.

Both studies acknowledge that professionals' engagement with reorientation efforts signifi-cantly depends on how the specific program fits with professionals' established practices. Forms of decoupling have been identified in cases where professionals perceived programs as dis-ruptive or trivial with regard to improving clients' health. In such cases, professionals only pre-tended to implement the particular program, while daily routines remained unchanged (McGivern \& Ferlie, 2007; Saario, 2012).

Professionals' role definition

A third critical dimension for the implementation of externally set programs is professionals' roledefinition. Professionals' role-definition is comprised of interacting social and cognitive com-ponents (identity, values, and knowledge), which are a product of shared experiences during extensive 
academic education and intra-professional communication with colleagues, as well as practical training (Ferlie et al., 2005). On the basis of qualitative case studies, Ferlie et al. (2005) investigated the implementation of healthcare programs in acute care settings in the UK. Professionals were found to have formed mono-disciplinary groups which defended their jur-isdictions as well as their established role-definitions, rather than collaborating on an inter-disci-plinary basis, as required by the particular organizational change program. Thus, existing social and cognitive boundaries within and between professionals hindered implementation. By con-trast, Levay and Waks (2009) found through interviewing the main professional groups - that in Swedish healthcare, professionals appreciated accreditation in a hospital laboratory and the national quality registries that contain information about diagnoses, treatments, and outcomes for different patient groups.

Implementation was facilitated for two reasons: (a) professionals felt the programs were consistent with their professional values and knowledge; and (b) professionals had sufficient opportunity and autonomy to adapt and refine the programs. Accordingly, pro-fessionals experienced the programs as part of their role while maintaining their autonomy.

The outcomes of both studies indicate that professionals' engagement with change programs corresponds particularly to the harmonization between the program and professionals' role definition. Compared to the case studied by Ferlie et al. (2005), in the Swedish case, professionals were involved in program specification and implementation leading to successful reorientation

(Levay \& Waks, 2009). Thus, following these studies, organizational change programs need to reflect professionals' role-definition by sharing their identities (e.g., language), values (e.g., client orientation), and knowledge (e.g., established research paradigms) in order to be implemented.

Discussion of strategies for hospital management to facilitate health promotion reorientation

Professional work as well as organizational configuration present specific challenges for reorientation efforts in hospitals and, in particular, organizational change programs which require modifications of professionals' work. Since health promotion may contradict long-existing knowledge and practices, primarily based upon the traditional biomedical definition of health, reorientation of hospitals towards health promotion becomes a challenging endeavour that is likely to fail. Professionals in hospitals, in particular, are able to effectively resist or ignore organizational change and strategic planning of hospital management (Mintzberg, 1997, 1979).

Considering the intricacy of health promotion reorientation of hospitals, specific managerial strategies are needed that encourage professionals to engage with health promotion program implementation. In this respect, we have outlined three critical dimensions that may be taken into account to facilitate organizational change such as the reorientation towards health pro-motion: professionals' status; professionals' practices; and professionals' role-definition. By con-sidering these three dimensions, we aim to provide suggestions, possibilities, and strategies whereby the decoupling between the operative core and hospitals' management can be bridged and whereby negotiation between professionals and management can be facilitated (see Table 1). With our 
suggestions, we follow Glouberman and Mintzberg (2001) who emphasized that, as long as professionals and hospital managers remain disconnected, nothing fundamental will change. Even if management in hospitals (as in any other professional organization) has limited steering options, hospital managers still have several possibilities to facilitate organiz-ational change and health promotion reorientation.

Strategies oriented towards professionals' status

We elaborated professionals' status as a critical dimension for their engagement with program implementation and thus facilitating or hindering effective health promotion practice in hospitals. Therefore, the ability of hospitals to match professionals' status with health promotion programs can be considered as one prerequisite for successful reorientation. As we have shown, pro-fessionals welcome change programs if they perceive that acquiring new skills, tasks, and respon-sibilities can enhance their professional status. From these findings, we delineate two possibilities for hospital management to facilitate health promotion reorientation: 'insider coalitions with nurses'; and 'prioritization and status incentives'.

Table 1. Strategies to facilitate health promotion reorientation among professionals.

\begin{tabular}{lcc} 
Professionals' status & Professionals' practices & $\begin{array}{c}\text { Professionals' } \\
\text { role-definition }\end{array}$ \\
\hline Insider coalitions with nurses & $\begin{array}{c}\text { Continuous participation of } \\
\text { professionals }\end{array}$ & Education \\
$\begin{array}{l}\text { Prioritization and status } \\
\text { incentives }\end{array}$ & Transformational leadership & Training \\
\hline
\end{tabular}

Insider coalitions with nurses

It has been suggested that professional groups respond differently to health promotion programs and that nurses are more supportive by comparison to doctors (Johansson, Stenlund, Lundström, \& Weinehall, 2010; Misevicience \& Zalnieraitiene, 2013). Correspondingly, Powell and Davies (2012), as outlined above, have found that nurses were more likely to implement pain-manage-ment services. The authors noted that pain management was perceived as a low-status task by highly professionalized physicians who were, thus, less likely to implement and engage with pain management. Along with this finding, we suggest that further research may investigate the question of whether health promotion is considered a low-status task among highly professio-nalized groups. So far, the health promotion literature indicates that health promotion has attracted notice among nurses (De Leeuw, 2009). Accordingly, we argue that by actively approaching nurses, hospital managers can help them to acquire new skills and competencies and thereby to expand their field of responsibility (Abbott, 1988). Here, we largely follow Glouberman and Mintzberg (2001), who have shown that, in hospitals, managers are more likely to address nurses than physicians because 
managers and nurses share their tight commitment to the (hospi-tal) organization and thus form an 'insider coalition'. Physicians, according to the authors, are more likely to relate to their professional association outside the hospital, as we have elaborated above. The common ground of nursing and management offers a crucial starting point for facil-itating organizational change. Moreover, paying particular attention to nursing in health pro-motion reorientation has several other advantages: nursing, as a focal point for hospital managers, seems appropriate because healthcare requires more and more devoted, continuous, holistic, and pre-emptive care (Pelikan et al., 2005) than the narrow, episodic, and radical cures primarily provided by physicians (Mintzberg, 2012). Furthermore, nurses, as the largest workforce in hospitals, are in the best position to facilitate reorientation towards health promotion (Whitehead, 2005). Yet, building coalitions merely with nursing potentially leads to conflicts within and between professional groups because of differing degrees of professional autonomy, with medicine at the pinnacle and nursing and allied health professionals representing subordinate groups (Freidson, 2001). Therefore, complementary strategies to consider professionals' status and to overcome decoupling are needed.

Prioritization and status incentives

To support organizational change towards health promotion in hospitals, management can offi-cially and conspicuously prioritize health promotion. Thereby, hospital managers are able to raise awareness for health promotion, to emphasize that health promotion has a top-ranking status within the organization, to make it more attractive to professionals and thus, to win over a broad range of professionals. The relevance of making health promotion an organizational pri-ority has also been emphasized in the health promotion literature. Pelikan (2007) demands that hospital management integrate health promotion into hospitals' 'written vision, mission state-ment, policies, action plans, guidelines, manuals and protocols' (p. 267). However, prioritizing only represents the formal side of hospital organizations and, as we have indicated previously, formal arrangements do not automatically translate into changes among the operative core because autonomous professionals have many opportunities to circumvent or resist formal requirements. To ensure that changes also occur in practice, incentives can be utilized. Applying incentives to facilitate change is anything but new. Monetary payments, especially in business organizations, are used to reward employees for their performance. In professional organizations like hospitals, we argue, status incentives can be offered by hospital managers. Status incentives including positional goods ('employee of the month'), job titles, fellowships, or prizes have been applied in universities as incentive devices to convey status on their professionals (Besley \&Ghatak, 2008). As both universities and hospitals can be understood as professional organizations (Mintzberg, 2012, 1979), status incentives may also represent an opportunity for hospital man-agers to facilitate professionals' engagement with health promotion. Future research may inves-tigate how status incentives work in hospital organizations to facilitate change. In line with Abbott's theory (1988), hospital managers may facilitate health promotion implementation if they ensure that professionals perceive health promotion as part of their 'professional project', a means to gain status by developing their professional expertise and expanding their territory. 
Successful reorientation in hospitals towards health promotion depends considerably on how health promotion programs dovetail with professionals' practices. As outlined above, organiz-ational change will be more likely if professionals consider the program to be an opportunity to improve their existing practices. To ensure that health promotion programs correspond to pro-fessionals' practices, we propose that hospital managers consider 'continuous participation of professionals' and 'transformational leadership' as closely intertwined strategies to facilitate health promotion reorientation.

Continuous participation of professionals

By suggesting continuous participation of professionals as a strategy for hospital managers to facilitate health promotion reorientation, we enlarge the well-established concept of participation in health promotion. So far, models of participation in health promotion have focused on the involvement of 'lay' people (read: clients and communities) (Green \& Tones 2010). Here, we argue that hospital managers can facilitate health promotion reorientation by ensuring health pro-motion programs are sensitive to established practices and represent opportunities for professional development and service improvement. Therefore, it is essential that the knowledge and perspectives of professionals working at the operative core be considered when deciding upon the appropriateness of health promotion programs as well as ways to implement them. By facilitating continuous participation of professionals, hospital management can enable professionals to yield the codified and systematized knowledge (Abbott, 1988) that particularly influences their work. Professionals can actively develop their own problematization of health promotion, articu-late their views on health promotion, and translate these views into sustainable decisions about health promotion reorientation. Moreover, continuous participation by professionals offers man-agement another opportunity to negotiate (Strauss et al., 1963) new forms of work and enables strategic venturing at the base rather than mere strategic planning at the top. Thereby, it can help hospital managers to prevent health promotion reorientation running into the 'administrative gap' that is caused by the disconnection and decoupling between management and clinicians (Mintzberg, 2012).

Transformational leadership

Transformational leadership can be considered as another strategy to facilitate health promotion reorientation. It has been elaborated that within professional organizations, such as hospitals, one cannot rely on 'strong leadership' to establish organizational change. Hospital managers cannot fully steer and control change among the operative core because professionals shield their prac-tices from other parts of the organization due to their professionalization and are far more respon-sive to their own hierarchies than to managerial hierarchies of formal authority (Abbott, 1988; Mintzberg, 1979). Consequently, for hospital managers who want to reorient their organizations towards health promotion, it is useful to adopt the role of enabler rather than merely providing directions. The 
notion of enabling is not new; it has been long advocated that leadership practice be about the interaction between the leader and followers rather than directive orders. For the hos-pital sector, Xisaragar, Samuels, and Stoskopf (2005) have shown that transformative leadership styles and partnering with professionals are most effective with respect to clinical outcomes and cost control, in contrast to leadership that is directive. In addition to empirical evidence for the advantages of transformational leadership, the relevance of enabling has also been emphasized as a key strategy in the Ottawa Charter (Green \& Tones, 2010; World Health Organization, 1986). However, in the Ottawa Charter, enabling is primarily framed as a strategy that helps people (read: clients or patients) to make healthy choices. Here, we argue for expanding the strat-egy to hospital managers who enable professionals to enact organizational change and thus make health promotion part of their practices.

Strategies oriented towards professionals' role-definition

Another critical dimension for professionals' engagement with program implementation included professionals' role-definition. We have shown that reorientation in hospitals frequently fails because organizational change programs do not adequately reflect professionals' identities, values, and knowledge. Following these findings, we suggest 'education' and 'training' are two closely intertwined strategies to advance health promotion reorientation.

Education

Education offers the opportunity to integrate health promotion into professionals' identities, values, and knowledge. Considering education as a strategy to encourage health promotion reorientation seems particularly suitable for young professionals who have not yet completed their academic education. Through education, professionals can become familiar with fundamental health promotion principles, values, targets, goals, and practices. As early as 1979, Henry Mintzberg emphasized educational programs and education curricula of professionals as a main strategy to change professionals' work. He argued that because of the decoupling between hospital management and professionals, organizational change has to start outside the organization. However, we expand on Mintzberg's argument that hospital managers can merely facilitate change among professionals outside the organization. As elaborated above, professionals' (academic) education depends considerably on practice-based training (Abbott, 1988) conducted on-site, i.e., in the hospital. Accordingly, hospital management can support the strengthening of health promotion values and competence within practice-based education and, thereby, ensure that professionals become familiar, from the beginning of their education, with the more resource-oriented conception of health (World Health Organization, 1986). Focussing on increasing health promotion knowledge, but also ensuring health promotion integration into professionals' role-definition, we further expand on recent discussions on organizational capacity-building to facilitate health promotion reorienta-tion (Hawe et al., 1997; Röthlin, 2013). The relevance of professionals' education to enable change has 
been emphasized in a Lancet report (Frenk et al., 2010), in which the authors particularly argue professionals have to become familiar with a more holistic care provision - as emphasized by the Ottawa Charter (World Health Organization, 1986) - to adequately address the health challenges including chronic diseases - of the twenty-first century.

Training

Training presents another opportunity to make professionals familiar with health promotion. In contrast to education, training can also address experienced professionals. Through training, professionals can gain hands-on skills in integrating health promotion into their work and to develop their approach to care provision. The relevance of training as a possibility for hospital managers to influence professional practice has already been considered in health promotion. For example, the Baby-Friendly Hospital Initiative (BFHI), which aims to promote and support breastfeeding on maternity units, has specified a particular number of hours for training that professionals on maternity units are required to achieve (World Health Organization \& United Nation Children's Fund, 2009). During such training sessions, professionals acquire the necessary knowledge and skills to promote breastfeeding. Empirical BFHI studies support the supposition that training considerably facilitates BFHI implementation by professionals and emphasize train-ing as a considerable opportunity for professionals to exchange and discuss their experiences and ways to adapt the program to their work routines (e.g., Wieczorek, Schmied, Dorner, \& Dür, 2015). This example reveals the necessity of harmonizing professionals' values and identities with health promotion, as well as providing professionals with first-hand experience.

Conclusion

Professional autonomy and organizational decoupling are particular challenges for health promotion reorientation in hospitals. To date, strategies to foster health promotion in hospitals have largely been adapted from strategies designed for business organizations, including organ-izational development, which stress the establishment of new formal structures from which pro-fessionals often deviate in practice, total quality management that specifically highlights monitoring of professional performance in hospitals, or organizational capacity-building which largely emphasizes the resources of organization. By applying theories from the sociology of pro-fessions and organizational science, it has been argued in this paper that hospital management needs to rely on less direct steering strategies. Without asserting completeness, insider coalitions with nurses, prioritization and status incentives, continuous participation of professionals, and transformative leadership, as well as education and training, were identified as important strat-egies to facilitate change. While these present viable strategies for hospital managers, other factors, particularly in the organizational environment (e.g., national governance structures), may also influence health promotion reorientation. However, elaborating these factors would have been outside the scope of this paper, which specifically focused on challenges, possibilities, and strategies for managers inside 
the hospital. Further research may investigate whether and how factors within the organizational environment influence reorientation of hospitals towards health promotion.

Acknowledgements

The authors would like to thank Hermann Schmied, Florian Röthlin, and Daniela Rojatz as well as the anonymous reviewers for their valuable feedback on earlier drafts of this manuscript.

References

Abbott, A. (1988). The system of professions: An essay on the division of expert labor. Chicago: University Press.

Allsop, J. (2006). Medical dominance in a changing world: The UK case. Health Sociology Review, 15, 444- 457.

Armstrong, D. (2002). Clinical autonomy, individual and collective: The problem of changing doctors' be-haviour. Social Science \& Medicine, 55, 1771-1777.

Besley, T., \& Ghatak, M. (2008). Status incentives. The American Economic Review, 98, 206-211. doi: 10. $1257 /$ aer.98.2.206

Brandt, E., Schmidt, W., Dziewas, R., \& Groene, O. (2005). Implementing the health promoting hospitals strategy through a combined application of the EFQM excellence model and the balanced scorecard. In O. Groene \& M. Garcia-Barbero (Eds.), Health promotion in hospitals: Evidence and quality manage-ment (pp. 80-99). Copenhagen: WHO-Europe.

Correia, T. (2013). The interplay between managerialism and medical professionalism in hospital organis-ations from the doctors' perspective: A comparison of two distinctive medical units. Health Sociology Review, 22, 255-267.

De Leeuw, E. (2009). Have the health services reoriented at all? Health Promotion International, 24, 105- 107. doi: 10.1093/heapro/dap015 
Elston, M. A. (1991). The politics of professional power: Medicine in a changing health service. In J. Gabe, M. Calnan \& M. Bury (Eds.), The sociology of the health service (pp. 134-156). London: Routledge.

Elston, M. A. (2004). Decline of medical autonomy. In J. Gabe, M. Bury, \& M. A. Elston (Eds.), Key con-cepts in medical sociology (pp. 178-183). London: Sage Publications.

Ferlie, E., Fitzgerald, L., Wood, M., \& Hawkins, C. (2005). The nonspread of innovations: The mediating role of professionals. Academy of Management Journal, 48, 117-134. doi:

10.5465/AMJ.2005. 15993150

Freidson, E. (2001). Professionalism: The third logic. Cambridge: Polity Press.

Frenk, J., Chen, L., Bhutta, Z. A., Cohen, J., Crisp, N., Evans, T., ... Zurayk, H. (2010). Health professionals for a new century: Transforming education to strengthen health systems in an interdependent world. The Lancet, 376, 1923-1958. doi: 10.1016/S0140-6736(10)61854-5

Garcia-Barbero, M. (1998). Evolution of health care systems. In J. M. Pelikan, K. Krajic, \& H. Lobnig (Eds.), Feasibility, effectiveness, quality and sustainability of health promoting hospital projects (pp. 27-30). Gamburg: G. Conrad Health Promotion Publications.

Glouberman, S., \& Mintzberg, H. (2001). Managing the care of health and the cure of disease - Part I: Differentiation. Health Care Management Review, 26, 56-69.

Green, J., \& Tones, K. (2010). Health promotion: Planning and strategies (2nd ed.). London: SAGE. Groene, O., \& Garcia-Barbero, M. (2005). Health promotion in hospitals: Evidence and quality manage-

ment. Copenhagen: World Health Organization Regional Office for Europe.

Grossman, R., \& Scala, K. (1993). Health promotion and organizational development: Developing settings for health. Copenhagen: World Health Organization Regional Office for Europe.

Haug, M. (1988). A re-examination of the hypothesis of physician deprofessionalisation. Millbank Quarterly, 66, 48-56. 
Hawe, P., Noort, M., King, L., \& Jordens, C. (1997). Multiplying health gains: The critical role of capacity-building within health promotion programs. Health Policy, 39, 29-42.

Johansson, H., Stenlund, H., Lundström, L., \& Weinehall, L. (2010). Reorientation to more health promotion in health services: A study of barriers and possibilities from the perspective of health professionals.

Journal of Multidisciplinary Healthcare, 3, 213-224. doi: 10.2147/JMDH.S14900

Johnson, A., \& Baum, F. (2001). Health promoting hospitals: A typology of different organizational approaches to health promotion. Health Promotion International, 16, 281-287. doi:

10.1093/heapro/ 16.3.281

Lee, C. B., Chen, M. S., Chien, S. H., Pelikan, J. M., Wang, Y., \& Chu, C. M. Y. (2014). Strengthening health promotion in hospitals with capacity building: ATaiwanese case study. Health Promotion International. doi: 10.1093/heapro/dat089

Lee, C. B., Chen, M. S., \& Wang, Y. (2014). Barriers to and facilitators of the implementation of health pro-moting hospitals in Taiwan: A topdown movement in need of ground support. The International Journal of Health Planning and Management, 29, 197-213. doi: 10.1002/hpm.2156

Levay, C., \& Waks, C. (2009). Professions and the pursuit of transparency in healthcare: Two cases of soft autonomy. Organization Studies, 30, 509-527. doi: 10.1177/0170840609104396

McGivern, G., \& Ferlie, E. (2007). Playing tick-box games: Interrelating defences in professional appraisal. Human Relations, 60, 1361-1385. doi: 10.1177/0018726707082851

Mc Kinlay, J., \& Arches, J. (1985). Towards the proletarianization of physicians. International Journal of Health Services, 15, 161-195. doi: 10.2190/JBMN-COW6-9WFQ-Q5A6

Mintzberg, H. (1979). The structuring of organizations. New Jersey: Prentice-Hall. Mintzberg, H. (1997). Toward healthier hospitals. Health Care Management Review, 22, 9-18.

Mintzberg, H. (2012). Managing the myths of health care. World Hospitals and Health Services, 48, 4-7. Retrieved from http://www.mcgill.ca/desautels/sites/mcgill.ca.desautels/files/channels/attach/manag ing_the_myths_of_health_care.pdf 
Misevicience, I., \& Zalnieraitiene, K. (2013). Health promoting hospitals in Lithuania: Health professional support for standards. Health Promotion International, 28, 512-521. doi: 10.1093/heapro/das035 Numerato, D., Salvatore, D., \& Fattore, G. (2012). The impact of management on medical professionalism:

A review. Sociology of Health \& IIIness, 34, 626-644. doi: 10.1111/j.1467-9566.2011.01393.x Parsons, T. (1969). Research with human subjects and the 'professional complex'. Daedalus, 98, 325360. Pelikan, J. M. (2007). Health promoting hospitals - Assessing developments in the network. Italian Journal

of Public Health, 4, 261-270. Retrieved from http://www.hauora.co.nz/assets/files/Tools/Health\% 20Promoting\%20Hospitals\%20Austria\%5B1\%5D.pdf

Pelikan, J. M., Dietscher, C., Krajic, K., \& Nowak, P. (2005). Eighteen core strategies for health promoting hospitals. In O. Groene \& M. Garcia-Barbero (Ed.), Health promotion in hospitals: Evidence and quality management (pp. 46-63). Copenhagen: World Health Organization Regional Office for Europe.

Pelikan, J. M., Dietscher, C., \& Schmied, H. (2013). Health promotion for NCDs in and by hospitals: A health-promoting hospital perspective. In D. V. McQueen (Ed.), Global handbook on noncommunicable diseases and health promotion (pp. 442-460). New York: Springer.

Pelikan, J. M., Krajic, K., \& Dietscher, C. (2001). The health promoting hospital (HPH): Concept and devel-opment. Patient Education and Counseling, 45, 239-243. doi: 10.1016/S0738-3991(01)001872

Powell, A. E., \& Davies, H. T. O. (2012). The struggle to improve patient care in the face of professional boundaries. Social Science \& Medicine, 75, 807-814. doi:

10.1016/j.socscimed.2012.03.049

Röthlin, F. (2013). Managerial strategies to reorient hospitals towards health promotion: Lessons from organ-izational theory. Journal of Health Organization and Management, 27, 747-761. doi: 10.1108/JHOM-07-2011-0070

Saario, S. (2012). Managerial reforms and specialized psychiatric care: A study of resistive practices per-formed by mental health practitioners. Sociology of Health \& Illness, 34, 896-910. doi: 10.1111/j. 1467-9566.2011.01439.x 
Saks, M. (2010). Analyzing the professions: The case for the neo-Weberian approach. Comparative Sociology, 9, 887-915. doi: 10.1163/156913310X522624

Stichweh, R. (1997). Professions in modern society. International Review of Sociology, 7, 95-102. doi: 10. 1080/03906701.1997.9971225

Strauss, A., Schatzman, L., Ehrlich, D., Bucher, R., \& Sabshin, M. (1963). The hospital and its negotiated order. In E. Freidson (Ed.), The hospital in modern society (pp. 147-169). London: The Free Press of Glencoe.

Timmons, S., Coffey, F., \& Vezyridis, P. (2014). Implementing lean methods in the mmergency department: The role of professions and professional status. Journal of Health Organization and Management, 28, 214-228. doi: 10.1108/JHOM-10-2012-0203

Vanderstraeten, R. (2007). Professions in organizations, professional work in education. British Journal of Sociology of Education, 28, 621-635. doi: 10.1080/01425690701505516

Weick, K. E. (1979). The social psychology of organizing. Reading, Mass: Addinson-Wesley Publ. Whitehead, D. (2004). The European health promoting hospitals (HPH) project: How far on? Health Promotion International, 19, 259-267. doi: 10.1093/heapro/dah213

Whitehead, D. (2005). Health promoting hospitals: The role and function of nursing. Journal of Clinical Nursing, 14, 20-27. doi: 10.1111/j.1365-2702.2004.01012.x

Wieczorek, C. C., Schmied, H., Dorner, T. E., \& Dür, W. (2015). The bumpy road to implementing the Baby-Friendly Hospital Initiative in Austria: A qualitative study. International Breastfeeding Journal, 10(3), 1-14. doi: 10.1186/s13006-015-0030-0

Wise, M., \& Nutbeam, D. (2007). Enabling health systems transformation: What progress has been made in re-orienting health services? Promotion \& Education, 14, 23-27. doi: $10.1177 / 10253823070140020801 x$

World Health Organization. (1986). Ottawa charter for health promotion. Geneva: WHO.

World Health Organization, \& United Nation Children's Fund. (2009). Baby-friendly hospital initiative: revised updated and expanded for integrated care. Geneva: WHO. 
Xisaragar, S., Samuels, M. E., \& Stoskopf, C. H. (2005). Physician leadership styles and effectiveness: An empirical study. Medical Care Research and Review, 62, 720-740. doi:

$10.1177 / 1077558705281063$ 